\title{
Sensorless position estimation of simulated direct driven hydraulic actuators
}

\author{
T. Sourander, M. Pietola, T. Minav, and H. Hänninen \\ Department of Mechanical Engineering, Aalto University School of Engineering, Espoo, Finland \\ E-mail: tom.sourander@aalto.fi,matti.pietola@aalto.fi, tatiana.minav@aalto.fi, henri.hanninen@aalto.fi
}

\begin{abstract}
In this study, sensorless position control of hydraulic cylinders is investigated. Direct driven hydraulics units are utilized as a prime mover. Direct driven hydraulics is a valveless pump controlled hydraulic system that uses an electric motor to drive pumps for a single actuator. This brings energy saving and controllability advantages to traditional valve controlled hydraulics. Advantages and disadvantages of various types of position sensors, which are available on the market were investigated for hydraulic cylinder application. These sensors, while accurate, have been noted to be rather expensive and not suitable for harsh environment applications. Virtual sensors can provide an alternative to physical position sensors. Using only torque and speed data received from electric motor controller it is possible to simulate the position of a cylinder, provided that all relevant parameters are known. Simulation model of direct driven hydraulic system of a mining loader test platform was realized using Matlab/Simulink Simscape blocks. Results within the simulation show that the model can reach an accuracy within a few millimeters for a single cycle. A cumulative error for repeated cycles was observed, which recommends simple cylinder end or middle point proximity sensors to be used as reference points.
\end{abstract}

Keywords: Sensorless position control, Virtual sensors, Direct driven hydraulics, Electrohydraulic actuator

\section{Introduction}

Improving the energy efficiency of hydraulic powered machinery has led to increasing efforts to find solutions for replacing conventional systems. In industrial and automotive fields, the common solution has been electric powertrains due to the high efficiency of electric power transfer and motors. In hydraulics, electric motors have generally been utilized in stationary applications however, the hydraulic systems themselves traditionally have been valve-controlled that have issues with flow losses. In addition, hydraulic machines are experiencing more automatization, which requires the implementation of more advanced control technologies.

To remedy this, increasing interest has been devoted to electric-driven pump-controlled actuators, which work as a hydrostatic transmission for cylinders. Unlike traditional hydrostatic transmissions, in which a combustion engine powered variable displacement pump is driven at constant speed, electric motors provide fast response time, which allows the utilization of more affordable fixed displacement pumps. This offers not only increased energy efficiency due to reduced idling losses but also a chance for implementing a sensorless position control system for the cylinders utilizing sensor virtualization. The advantages are increased redundancy and reduced the dependency on expensive absolute position sensors normally utilized in cylinders.
With increased use of automated processes in hydraulic applications such as mobile machines, the role of position sensors has become a vital part of these systems. Several types of position sensors, both internal and external types exist for measuring the linear movement of hydraulic cylinders. However, even position sensors that seem simple and robust can be surprisingly costly or challenging to implement in applications requiring reliability and robustness in harsh environments. It has also been noted that wires and connectors can be prone to damage and devices relying on position sensors can be incapacitated if an error or malfunction appears in sensors. Thus, it would be useful if the position of hydraulic actuated joints could be measured by indirect means for redundancy and cost saving. [1]

Cylinder internal sensors apart from draw-wire types require drilling a hole in the piston to mount a transducer rod, which significantly increases cost. Longer pistons require longer bore holes, which increases the difficulty and the cost of manufacturing internal sensors for large cylinders. Furthermore, if an internal sensor malfunctions, the entire cylinder needs to be disassembled. External types are cheaper and easier to install due to the transducer being mounted on the surface of the cylinder. However, external mounting causes the sensor and its cabling to be more vulnerable in harsh environments. Proper protection of these is required, which complicates servicing and replacing parts. [1] 
Therefore, to reduce the amount of sensors needed in machines and to provide a level of redundancy, sensor virtualization has been increasingly researched. This method utilizes information from other sensors to indirectly calculate a desired value based on a physical model of the process. Examples of application utilizing sensor virtualization include a car electric window position sensing from measuring current fluctuations of a DC drive motor [2], calculating fluid level in process tank and calculating the thickness of a steel sheet on rolling mill [3]. It is often necessary to perform test measurements from real processes to validate and calibrate simulations and thus try to minimize any accumulative errors. While virtual sensors can lead to saving in component and mechanical design costs, other design costs and time will increase. However, with simulation becoming more routine in all design processes, planning virtual sensors could become more commonplace. As mentioned, sensor virtualization provides a method for implementing position control of pump-controlled hydraulic cylinders.

Traditional valve controlled open-loop hydraulics tend to waste power due to idling losses either through a pressure relief valve or open centered valves. To improve the efficiency of hydraulic power transfer, it is necessary to reduce wasted power during idling and partial flow to actuators. One solution is to move from valve-controlled systems to pump-controlled, in which a motor drives a pump to control the flow to a single actuator. Pumpcontrolled hydraulic cylinders are often known as electrohydrostatic actuators (EHA). In this study, a variation of EHA, Direct driven hydraulics (DDH) will be utilized. DDH uses an electric motor to drive a pump only when needed, which eliminates idling losses and reduces cooling requirements. Other benefits include reduced valve and pipe pressure losses due to requiring no directional valves and shorter pipelines. Pump-controlled hydraulic cylinders have been rare due to difference in the volume between the cylinder sides of single-rod cylinders and thus the required flow rate. This ratio problem has usually been solved by using double-rod cylinders where both sides of the cylinder piston have the same area and thus equal required flow [4, 5]. However, more space is needed for the double-rod cylinder. This can be acceptable in some applications and for short movements however, for instance in an excavator or a loader boom not often enough space is available for the opposite rod. While most EHA systems have used double-rod cylinders due to the ratio problem, systems with the more compact and common single-rod cylinders have been increasingly researched [6, 7]. Most common solutions to the ratio problem involve check valves in a single pump system or two pumps that ideally have the same output flow ratio as the cylinder.

Typically, the driving engine and pumps are often dimensioned to produce enough power to drive the actuators and overcome the losses. In DDH however, every flow resistance and pressure loss is undesired if it can be avoided since one advantage of DDH is shorter flow lines and less valves. Hoses and other pipelines tend to be ignored, either due to irrelevance and small effect on overall efficiency or simply having to dimension them according to how they can be fit inside a machine. In this research, the hose sizing was found to be a somewhat significant pressure loss source. This can sometimes be an unavoidable problem since the size can often be limited by the physical dimensions and movement of the machine.

Commonly the position control of these EHA systems have been realized by using cylinder position sensors. When accounting most benefits in a DDH system, it should in theory, be possible to estimate the position of a hydraulic actuator utilizing only information from the motor in a sensor virtualization algorithm. The idea is to use torque and speed data from a motor controller to calculate the pressure and flow produced by the pump and estimate the movement of the cylinder. However, in contrast to mechanical linkages, hydraulic power transfer lines always contains errors and losses compared to an ideal case due to properties of hydraulic fluids. Considering position control of a linear actuator, these errors are mainly caused by leakages through pumps but also somewhat by compressibility under high pressure and small leakage through cylinder piston seals. Leakages are dependent on various fluid properties, most importantly kinematic viscosity, and pressure according to [8].

Examples of previous research on sensorless position estimation of electro-hydraulic cylinders include position estimation of a DDH actuated cylinder with measuring the pump leakage in the locked position and calculating a slip coefficient that accounted for all leakages [8] and sensorless position control in an electro-hydraulic forklift [9]. These studies were based on measurements and did not account for temperature changes and [9] assumed constant pump efficiencies. Results obtained in both showed error in the range of $1-3 \%$ during lifting and lowering. Also in [8], accumulation of error was observed in repeated liftlower cycles due to inaccuracy in pressure estimation.

This study expanded on the research of sensorless position calculation of DDH cylinders by investigating the feasibility of sensorless position control of a DDH actuated hydraulic bucket arm mechanism of a test platform mining loader. The approach was to calculate the position of a two hydraulic cylinder actuating a bucket arm mechanism using only data from the servomotor controllers driving the pumps. The position calculation was realized by simulating the interaction between the DDH unit pumps and cylinder movement with various cylinder loads and oil temperatures. The remainder of this paper is organized as follows. Section 2 introduces test platform, its simplified simulation model and components and explains the operational principles of the system. Simulation results and analysis of error are described in Sections 3. Sections 4 and 5 contain discussion and conclusions, respectively.

\section{Simulation model of the test platform}

The simulation model is based on a mining loader of conventional diesel hydraulic type that had its original 
hydraulic system replaced with DDH units and power system with a diesel-electric hybrid drivetrain. The front section consists of a boom and bucket. The boom is actuated by two parallel cylinders and the bucket by one cylinder. The base of the bucket cylinder is attached to a linkage mechanism that keeps the bucket angle stationary during the lifting of the boom. Figure 1 shows a 3D visualized model of this. Table 1 presents relevant information for the cylinders. Cylinder frictions were based on previous measurements with smaller cylinders and linearly scaled up to the loader cylinder dimensions [10].

The DDH units are designed to produce flow rates to both cylinder sides in a ratio that is as close as possible to the ratio of the cylinder areas. The units consist of an electric motor, motor controller, belt reduction transmission for fine-tuning the displacement ratios, intermeshing gear pumps [11], pressure relief valves, anti-cavitation valves, cylinder safety valves and oil reservoir.

Table 1. Relevant parameters for the mining loader hydraulic cylinders.

\begin{tabular}{lll}
\hline Parameter & Boom cylinder & Bucket cylinder \\
\hline Stroke $(\mathrm{mm})$ & 311.15 & 850 \\
\hline A-side area $\left(\mathrm{mm}^{2}\right)$ & 10261 & 18050 \\
\hline B-side area $\left(\mathrm{mm}^{2}\right)$ & 7096.9 & 11847 \\
\hline Area ratio & 1.4458 & 1.5236 \\
\hline $\begin{array}{l}\text { Static friction }(\mathrm{N}) \\
{[10]}\end{array}$ & 570 & 760 \\
\hline $\begin{array}{l}\text { Coulomb friction } \\
(\mathrm{N})[10]\end{array}$ & 170 & 220 \\
\hline $\begin{array}{l}\text { Viscous friction } \\
(\mathrm{N} /(\mathrm{m} / \mathrm{s}))[10]\end{array}$ & 41000 & 41000 \\
\hline
\end{tabular}

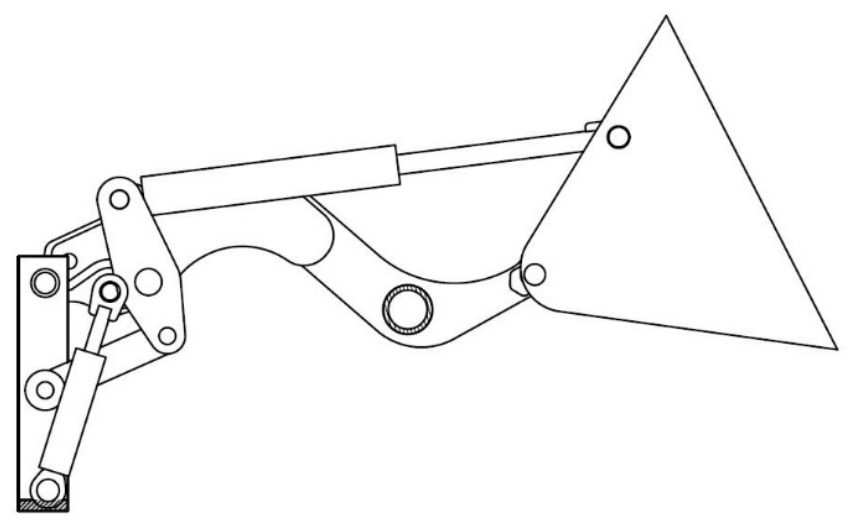

Figure 1. Visualization model of the mining loader bucket arm.

Hydraulic circuit diagram of the boom DDH unit is shown in fig. 2. The bucket DDH unit is identical with only different sized pumps and one cylinder. The instrumentation of the DDH units consist of pressure [12], temperature [13] and cylinder rod position wire-distance sensors [14]. Power is received from a lithium-titanate battery pack [15] that is recharged by the main hybrid power system [16]. Table 2 presents relevant parameters of the chosen pumps. Note that $\mathrm{x} 2$ in pump name means that the pumps are double chambered and the displacement in the name is for one chamber. X2 at the end means two parallel pump units, which will work as a single pump unit.

In a DDH system, the pump speed corresponds to fluid flow and torque to pressure, which in an electric motor can be measured as voltage and current. Correspondingly, the fluid flow rate affects the speed of a cylinder and pressure on the force. There are multiple sources for non-linearities and errors caused by the nature of hydraulics and its components, which makes calculating positions of the cylinders challenging. In addition, parameters of some components are based on estimations and simple calculations as measuring them would be impractical.

The estimation of cylinder rod positions is based on a simulation model of the bucket arm hydraulic systems. The model consists of kinematics and hydraulics parts. The model is created in Matlab/Simulink using ready-made Simscape multibody for kinematics and Fluid power blocks for hydraulics. Due to the kinematics of the loader arm, the cylinder loads are not constant during a lifting and lowering cycle. Thus to simplify the calculation of required motor torque a simple cylinder model was used with a load force applied to each cylinder to simulate cylinder movement dependence on pressure and pump operation. Since pressure, pump speed and oil viscosity affect pump leakages, the tests are performed with increasing cylinder force and varying oil temperature at each subsequent cycle.

Hydraulic cylinder force is caused by pressure difference acting on the piston surfaces in both piston sides as in equation 1:

$$
F_{p}=\left(p_{A} A_{c y l_{A}}-p_{B} A_{c y l_{B}}\right) \eta_{h m_{c y l}},
$$

where $F_{p}$ is the piston force, $p_{\mathrm{A}}$ and $p_{\mathrm{B}}$ pressures on each piston side, $A_{\text {cyl__ }}$ and $A_{\text {cyl_B }}$ the areas of the piston sides and $\eta_{h m c y l}$ is the hydro-mechanical efficiency of the cylinder. Area on side B is smaller due to the piston rod taking part of the space.

Piston movement is caused by the pumps forcing fluid into the cylinder. The piston moves at speed of:

$$
v_{c y l}=\frac{Q_{p}}{A_{c y l}} \eta_{v_{c y l}},
$$

where $v_{c y l}$ is the movement speed if the piston, $Q_{p}$ the flow produced by the pump and $\eta_{v_{-} c y l}$ the volumetric efficiency of the cylinder. The pump is able to produce flow dictated by its rotational speed:

$$
Q_{p}=\eta_{v_{p}} V_{p} \omega
$$

where $Q_{p}$ is flow rate of the pump, $\eta_{v-p}$ the volumetric efficiency of the pump or relative leakage back through the pump caused by pressure, $V_{p}$ is rotational displacement and $\omega$ is rotational speed. 
The pump volumetric efficiency is particularly important here as majority of the leakage losses are through the pump. The volumetric efficiency factor depends primarily on pressure difference between the pumping elements, gears in this case and viscosity of the oil. Various factors affect the pump specific efficiency curves, mostly clearance gaps between the gears and the chamber surface. It is known that volumetric efficiency has a more significant effect on total efficiency. Hydromechanical efficiency is affected by the internal friction of the pump, which is in turn affected by the lubricating effect of the leakage flow. Thus, the mechanical efficiency is also dependent on pressure and oil viscosity as well as the rotational speed of the pump [17]. Therefore, this simulation model uses nominal efficiencies from the manufacturer's datasheet. Efficiency variation is calculated within the pump model with the volumetric efficiency based on Hagen-Poiseuille laminar pipe flow model.

Table 2. Relevant parameters for the boom and bucket DDH unit pumps [11].

\begin{tabular}{|c|c|c|c|c|}
\hline \multirow[t]{2}{*}{ Parameter } & $\begin{array}{l}\text { Boom } \\
\text { pumps } \\
\text { A-side }\end{array}$ & $\begin{array}{l}\text { Boom } \\
\text { pumps } \\
\text { B-side }\end{array}$ & $\begin{array}{l}\text { Bucket } \\
\text { pumps } \\
\text { A-side }\end{array}$ & $\begin{array}{l}\text { Bucket } \\
\text { pumps } \\
\text { B-side }\end{array}$ \\
\hline & $\begin{array}{l}\text { PGI100 } \\
-008 \times 2 \\
\text { X2 }\end{array}$ & $\begin{array}{l}\text { PGI100 } \\
- \\
013+01 \\
1\end{array}$ & $\begin{array}{l}\text { PGI100 } \\
-016 \times 2 \\
\text { X2 }\end{array}$ & $\begin{array}{l}\text { PGI100 } \\
-022 \times 2\end{array}$ \\
\hline $\begin{array}{l}\text { Total } \\
\text { displacement } \\
\left(\mathrm{cm}^{3} / \mathrm{rev}\right)\end{array}$ & $\begin{array}{c}15.8 * \\
2= \\
31.6\end{array}$ & 24.2 & $\begin{array}{c}31.6^{*} \\
2= \\
63.2\end{array}$ & 44.4 \\
\hline $\begin{array}{l}\text { Maximum } \\
\text { circuit work } \\
\text { pressure (bar) }\end{array}$ & 270 & 70 & 70 & 172 \\
\hline $\begin{array}{l}\text { Nominal } \\
\text { volumetric } \\
\text { efficiency at } \\
250 \text { bar and } \\
1450 \mathrm{rpm}\end{array}$ & 0.93 & 0.94 & 0.95 & 0.95 \\
\hline $\begin{array}{l}\text { Nominal } \\
\text { hydromechanic } \\
\text { al efficiency at } \\
250 \text { bar and } \\
1450 \mathrm{rpm}\end{array}$ & 0.91 & 0.91 & 0.92 & 0.93 \\
\hline $\begin{array}{l}\text { Maximum } \\
\text { rotational } \\
\text { speed }(\mathrm{rpm})\end{array}$ & 4200 & 4000 & 4000 & 3600 \\
\hline $\begin{array}{l}\text { Gear ratio, } \\
\text { motor to pump }\end{array}$ & $28 / 41$ & $41 / 47$ & $28 / 44$ & $44 / 47$ \\
\hline $\begin{array}{lr}\text { A- and } & \text { B-side } \\
\text { geared } & \text { flow } \\
\text { ratio } & \end{array}$ & & & & \\
\hline
\end{tabular}

The torque required to run a pump depends on the pressure it needs to produce:

$$
T_{p}=\frac{V_{p} \Delta p}{\eta_{h m}},
$$

where $T_{p}$ is pump torque, $\Delta p$ pressure difference between pump outlet and inlet and $\eta_{h m}$ hydro-mechanical efficiency that consists of friction of mechanical parts and fluid flow.

Hydromechanical efficiency is calculated with equation 4 and volumetric efficiency from equation 3:

$$
\begin{gathered}
\eta_{h m}=\frac{V_{p} \Delta p}{T_{p}}, \\
\eta_{v}=\frac{Q_{p}}{V_{p} \omega},
\end{gathered}
$$

\section{Boom hydraulic circuit}

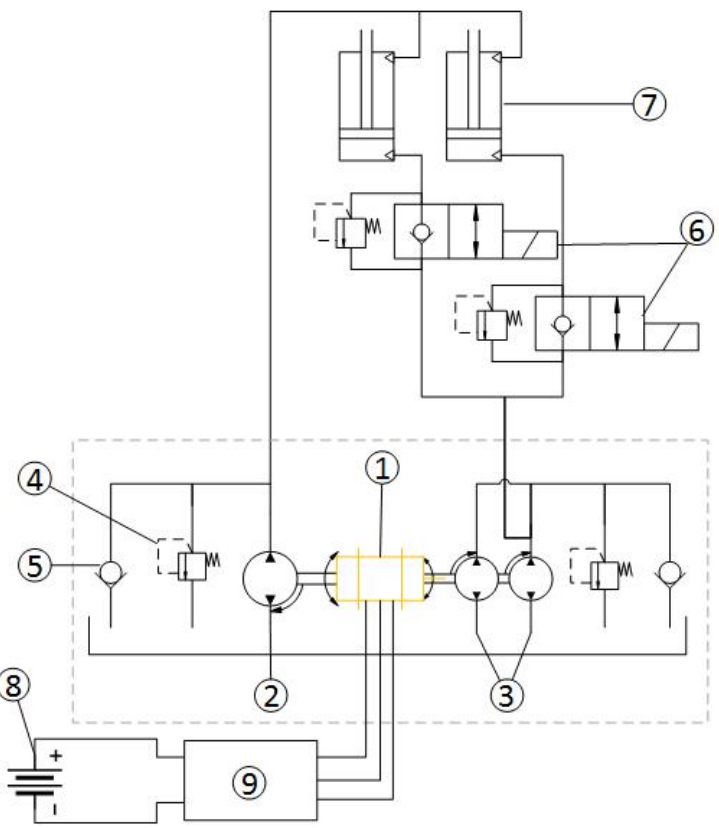

\begin{tabular}{lll}
\hline & Component & Model \\
\hline $\mathbf{1}$ & Electric motor & Motenergy ME1304 \\
\hline $\mathbf{2}$ & B-side pump & HYDAC PGI100 \\
\hline $\mathbf{3}$ & A-side pumps & HYDAC PGI100 \\
\hline $\mathbf{4}$ & Pump pressure relief valve & HYDAC DB10P-01 \\
\hline $\mathbf{5}$ & Anti-cavitation valve & HYDAC RV12A-01 \\
\hline $\mathbf{6}$ & Safety valves & HYDAC WS16ZR-01 \\
\hline $\mathbf{7}$ & Hydraulic cylinder & EJC90 original \\
\hline $\mathbf{8}$ & Battery & Altairnano 96 V \\
\hline $\mathbf{9}$ & Motor controller & Sevcon Gen 4 Size 6
\end{tabular}

Figure 2. Components of the boom DDH unit. [Courtesy of T. Lehmuspelto. Aalto University. 2016]

As an example, fig. 3 shows volumetric and hydromechanical efficiencies of several gear pump sizes in relation to pressure at nominal pump speed of $1450 \mathrm{rpm}$. 
Of these, sizes 8, 13, 16 and 22 are used. Size 8 efficiencies are available in a similar figure. In the figure, it can be seen that the volumetric efficiency decreases linearly with increasing pressure. In contrast, the hydromechanical efficiency increases rapidly at lower pressures and settles to almost constant but slightly increasing value at higher pressures. However, these efficiencies apply only for the oil viscosity and pump rotational speed used for measuring these graphs. Efficiencies at other oil viscosities and pump speeds are calculated as described. Direct measurements of volumetric and hydromechanical efficiencies is not feasible with the available test equipment, meaning that efficiencies will only be calculated in the simulation model and not measured.

Based on fig. 3 and the basic hydraulic equations of pump flow, pressure and efficiencies as well as piston force, a hypothesis can be formed for the cylinder movement under load. When cylinder payload increases, more pressure is needed to move it, which requires more pump torque. Higher pressure reduces the volumetric efficiency and thus causes more flow losses. Thus, the cylinder lifting movement against the load by flow produced by a pump revolution should decrease and reversely the lowering movement should increase. Figure 4 summarizes a diagram of the interaction between different parts and factors related in the sensorless position calculation process.

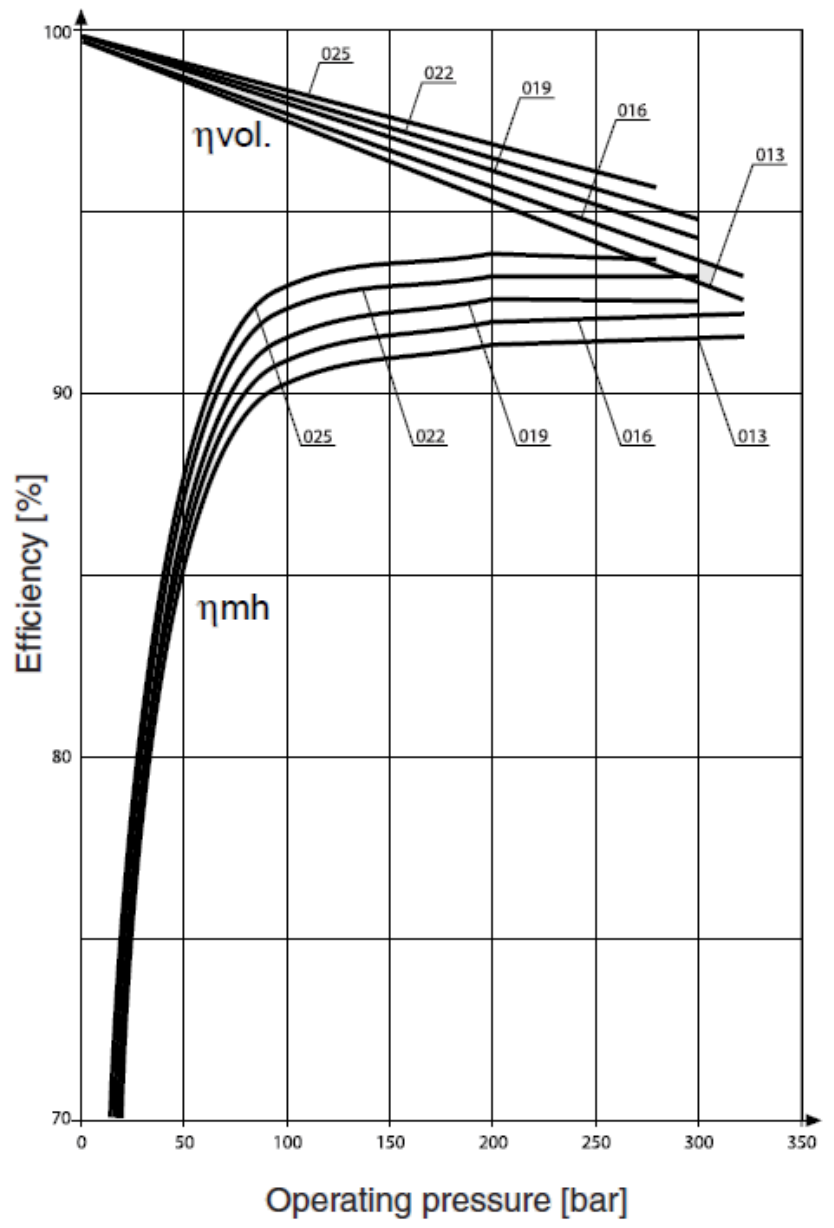

Figure 3. Efficiencies of several HYDAC gear pump sizes with VG46 equivalent oil at speed of $1450 \mathrm{rpm}$. [11]

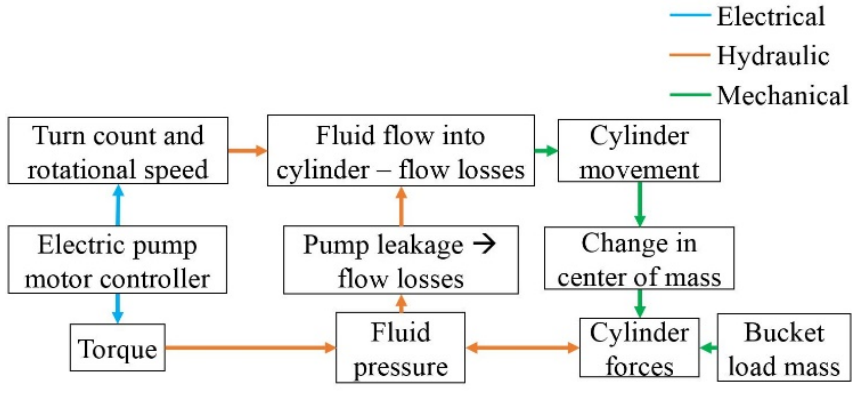

Figure 4. Relation between DDH simulation parts in sensorless position control.

In this study, models of the boom side DDH units is used as an example. In fig. 5 simplified version of the boom hydraulics blocks are presented. The hydraulics model is built based on the original schematics. Input for the pumps is produced by an ideal rotational velocity source that is supposed to act as a speed controlled motor. Pipelines add a significant amount of flow resistance and thus pressure loss. They also provide additional hydrostatic pressure dampening by allowing the pipelines to expand, which is important for the stability of the model as otherwise the model would be too stiff to allow proper interaction between the hydraulic and the kinematic parts. The safety valves are closed during lifting and opened during lowering according to motor speed. Some parameters of valves such as maximum opening areas are not given in manufacturer datasheets so the values are calculated from other information. Oil used is based on Shell Tellus T 32, which is VG32 equivalent hydraulic oil meaning it has a kinematic viscosity of $32 \mathrm{~mm}^{2} / \mathrm{s}$ at temperature of $40{ }^{\circ} \mathrm{C}$. Viscosity dependancy on temperature data is taken from Shell Tellus T oils datasheet [18].

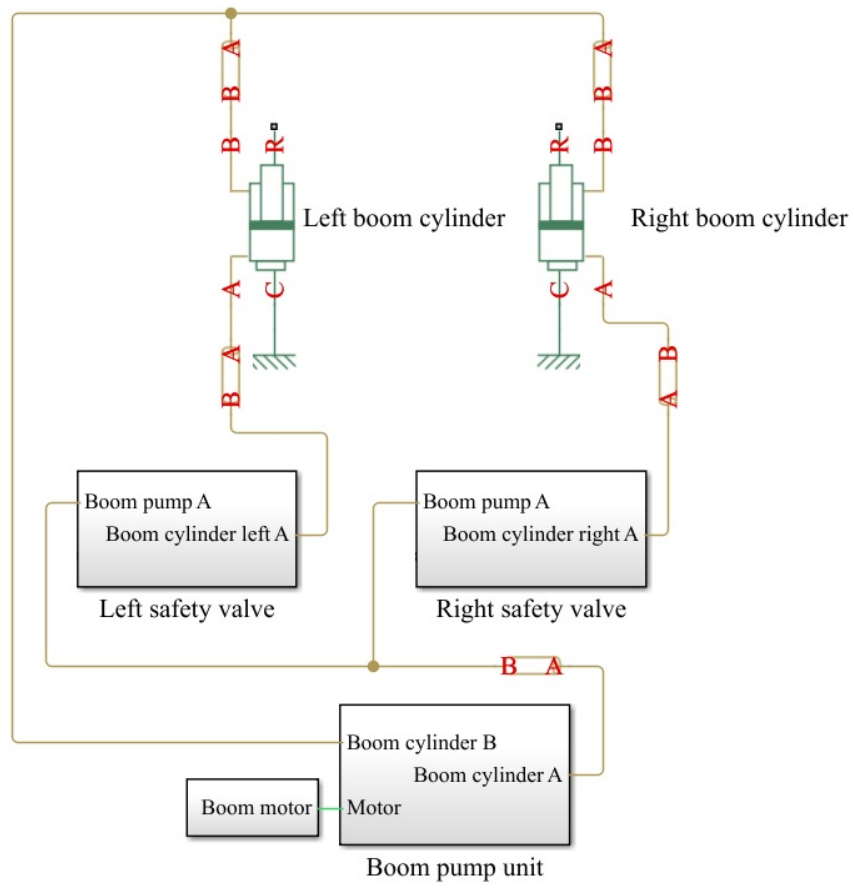

Figure 5. Simplified presentation of the Simscape model blocks used for modelling the boom DDH and cylinders. 


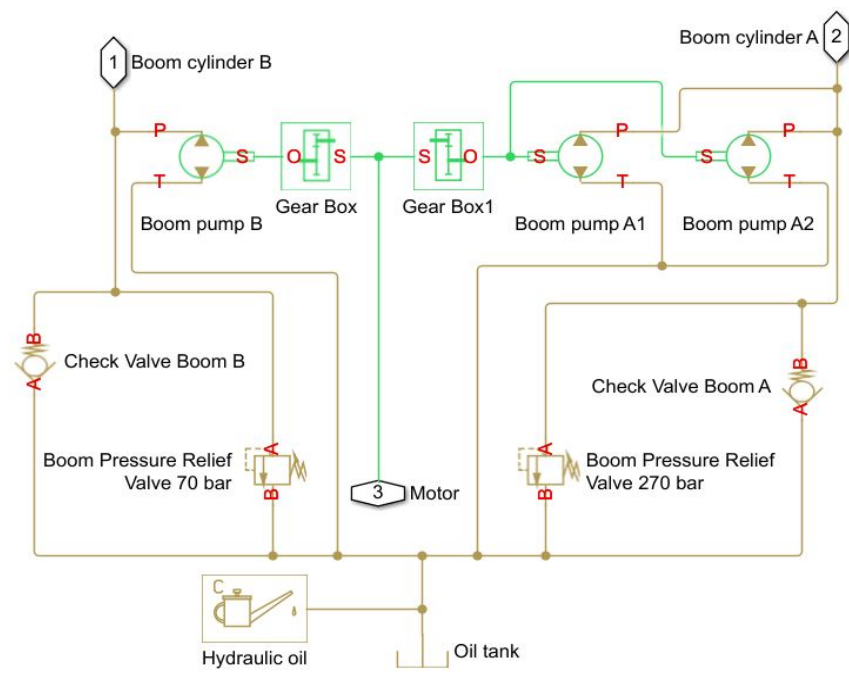

Figure 6. Simplified model of the boom pump system.

Figure 6 illustrates a simplified model of the boom pump system. The pumps are presented by fixed displacement hydraulic machines, which can work in both pump and motoring modes. This allows the pumps to run freely in motoring mode during lowering movements and as such do not cause disruptions in flow as regular pump model blocks would. The pump model has included loss calculation for leakage and friction. The losses can be computed either analytically or from table data efficiencies. Since it is often only necessary to verify whether the pump has specified parameters that are close enough to required, the manufacturer datasheets of the pumps only provide volumetric and mechanical efficiencies at one specific oil viscosity and pump speed [11]. As it was not feasible to perform leakage measurements with the real pumps, it was not possible to form lookup tables for the pump efficiencies at various oil temperatures and pump speeds, which is why the analytical method was utilized. For the sake of simplifying the problem, it is assumed that the physical properties of the pumps and other hydraulic components such as sealant wear, do not change. [19]

The analytical efficiency calculation uses nominal parameters of the pump to calculate Hagen-Poiseuille coefficient for laminar pipe flows. The nominal parameters of rotational speed, oil kinematic viscosity and density, pressure gain, volumetric and mechanical efficiencies are taken from the pump datasheet. The nominal rotational speed is $1450 \mathrm{rpm}$, oil kinematic viscosity is $46 \mathrm{~mm}^{2} / \mathrm{s}$ at temperature of $40{ }^{\circ} \mathrm{C}$, density is $872 \mathrm{~kg} / \mathrm{m}^{3}$ at temperature of $15{ }^{\circ} \mathrm{C}$ and pressure gain is the pump rated pressure of 250 bar. The efficiencies are taken from graphs of fig. 4 at the points of nominal pressure. Additional parameters required are No-load torque, which is left as default of 0.5 $\mathrm{Nm}$ and friction torque vs pressure gain coefficient, which is calculated from the volumetric and total efficiencies and pump displacement. [11, 17, 18]

Other parameters that were not possible to obtain from datasheets include cylinder frictions and hose flexibility. The cylinder frictions were estimated based on previous measurements of smaller cylinders and scaled to the size of the mining loader cylinders [10]. While this method does not provide the most accurate estimates due to differences in cylinder construction and seals, it grants a perspective to what scale the actual cylinder frictions are.

Friction torque $\tau_{\text {Fric }}$ is calculated according to equation 7:

$$
\begin{gathered}
\tau_{0}+K_{T P}|\Delta p| \tanh \left(\frac{4 \omega}{\omega_{\text {Thresh }}}\right), \\
\tau_{\text {Fric }}=i
\end{gathered}
$$

where $\tau_{0}$ is no-load torque, $K_{T P}$ is friction torque vs pressure gain coefficient, $\Delta p$ is the current pressure gain, $\omega$ is current pump angular velocity and $\omega_{\text {Thresh }}$ is threshold angular velocity between pump and motor mode transition.

The is friction torque vs pressure gain coefficient is calculated as:

$$
K_{T P}=1.5915 * 10^{-7} * V_{p} *\left(\frac{\eta_{v, N o m}}{\eta_{T o t}}-1\right)
$$

where $V_{p}$ is pump displacement, $\eta_{v, \text { Nom }}$ is the volumetric efficiency at nominal state and $\eta_{T o t}$ is total efficiency. The

Leakage flow $q_{\text {Leak }}$ is calculated as the current pump pressure gain times the Hagen-Poiseuille coeffcient $K_{H P}$ :

$$
q_{\text {Leak }}=K_{H P} \Delta p
$$

The Hagen-Poiseuille coefficient in this model is calculated as in:

$$
K_{H P}=\frac{v_{N o m}}{\rho v} \frac{\rho_{\text {Nom }} \omega_{\text {Nom }} V_{p}}{\Delta p_{\text {Nom }}}\left(1-\eta_{v, \text { Nom }}\right)
$$

where $v_{\text {Nom }}$ is the oil kinematic viscosity at nominal state, $v$ is the current kinematic viscosity, $\rho_{\text {Nom }}$ is the nominal oil density, $\rho$ is the current oil density, $\omega_{N o m}$ is the nominal pump angular velocity and $\Delta p_{N o m}$ is the nominal pressure gain.

Due to lack of data on the oil density dependance on temperature and the assumption that change in density with changing temperature is small with liquids, in this model the oil density stays constant. This assumption should not have a significant effect because as seen in eq. 5, the Hagen-Poiseuille coefficient depends on the ratio of nominal and current density. As the density change is small, it can be assumed that this the value of this ratio will stay close to one.

As mentioned, problems in modelling the loader arm are caused by changing cylinder load during the movement as well as stiffness of the combined hydraulics and kinematic model. Thus, the model was reduced to only the cylinders with load forces applied to the piston rods. The test load 
force affecting a cylinder was set between a small force of $1 \mathrm{kN}$ to a force that causes the cylinder pressure to be at relief valve pressure. Maximum lift force for both boom cylinders is about $554.1 \mathrm{kN}$ and for the bucket cylinder it is about $203.8 \mathrm{kN}$. When the relief valves start to open, part of the flow is diverted through them, which causes the cylinder position calculation process be no longer valid since it assumes that all flow leakage is through the pumps.

Results from running the simulation of cylinder movement under increasing loads and oil temperature, and measuring the required torque was saved as table data of motor torque vs cylinder movement per motor revolution. Positive and negative movement of the cylinders have their own tables with the motor direction determining which to use. Since the simulation was run at variable time step, the amount of motor revolutions per step varies. Thus, the current cylinder speed was calculated from the current motor speed and the cylinder movement per motor revolution. Integrating this calculated speed gives the cylinder movement during the time step. Cumulatively summing the movement steps gives the current position of the cylinder relative to the starting position. This requires the maximum time step to set short enough so that there can be no significant variations of these values during a step. Figure 7 shows the process flow and the parameters of the cylinder position calculation in the simulation.

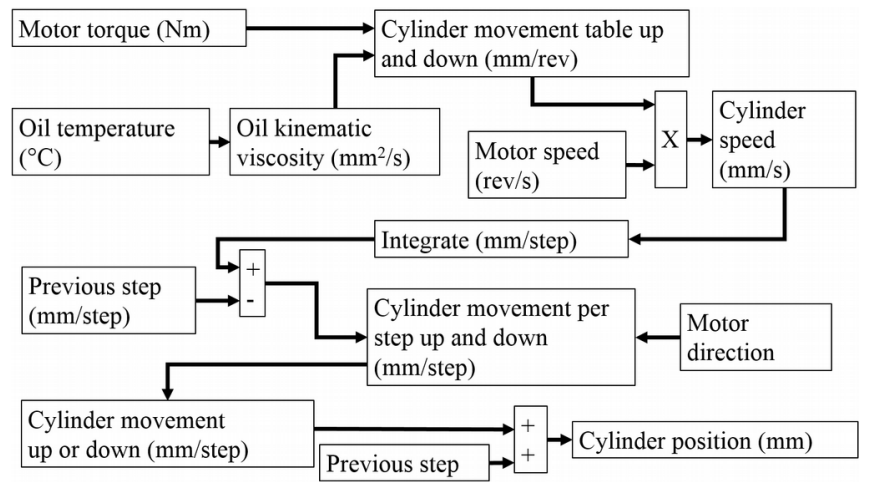

Figure 7. Process flow and parameters of the cylinder position calculation in the simulation model.

Figure 8 provides the explanation for the sensorless control of a DDH actuated cylinder. The user in this case is the high-level input source and can be either human or an automated process that provides control inputs to the DDH motor controller. The motor controller in turn feeds back torque and speed data from the motor sensors, which are used to calculate the cylinder position. This position data is then given to the user. This way the cylinder position calculation functions as a normal position sensor for the user.

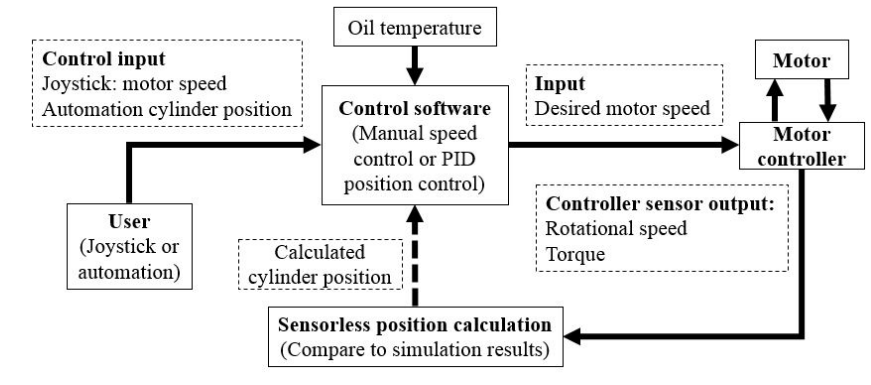

Figure 8. Diagram flowchart for the sensorless control of $\mathrm{DDH}$.

The following section introduces results of simulated liftlower cycles, which test the accuracy of the sensorless position calculation.

\section{Results}

Presented in figs. 9 and 10 illustrate examples of a simulation-based result of the boom and bucket cylinder movement per pump motor revolution in function of torque. The bucket motor torque is reverse to the boom due to the bucket cylinder rod-side being the lifting side and thus the motor is driven in negative direction. The figures illustrate that increasing cylinder load and pressure, and thus torque causes less cylinder movement per pump revolution during lifting due to increasing pump leakage and vice versa for lowering. Rapid drop at high torque in the lifting graph is caused by pressure reaching pressure relief valve limit. At higher temperatures, oil viscosity is lower thus causing more pump leakage and lower cylinder movement ratio. The sensorless position calculation is based on lookup tables consisting of these graphs at various temperatures.

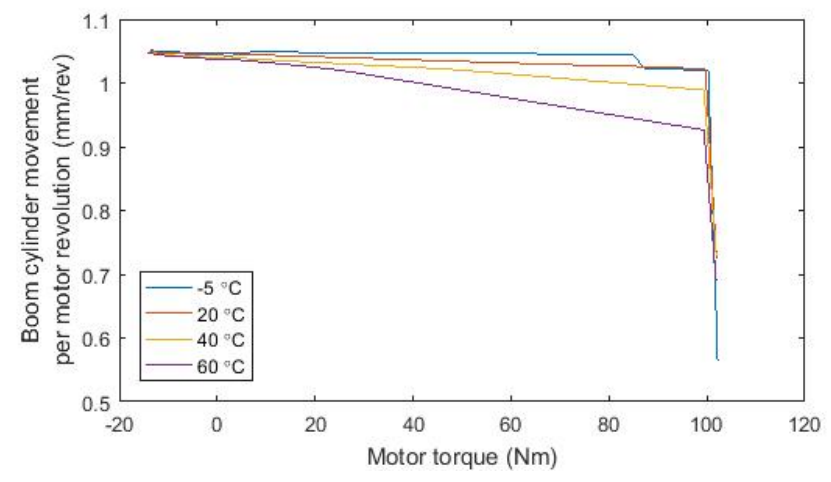

Figure 9. Boom cylinder movement per motor revolution in function of torque at various temperatures. 


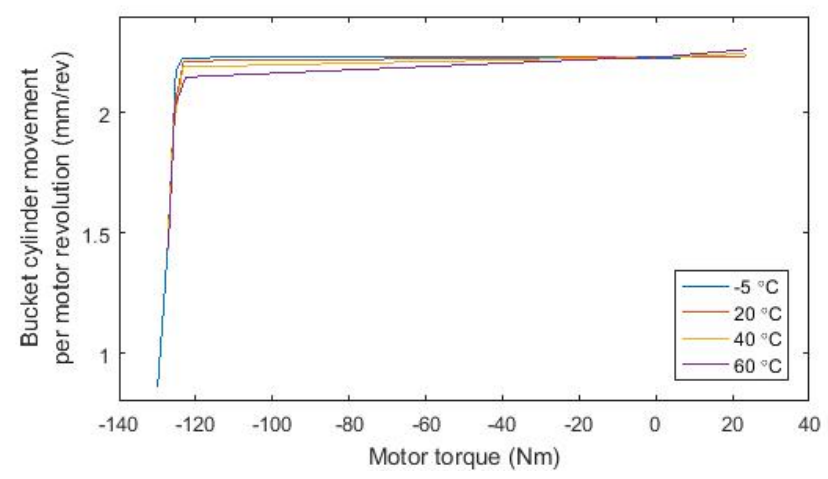

Figure 10. Bucket cylinder movement per motor revolution in function of torque at various temperatures.

Figure 11 shows the boom cylinder position at low cylinder load and fig. 12 with high load based on the simulated actual cylinder position and the position calculated with the look up tables. The cycle consist of running the motor for a fixed amount of time at constant speed. In these figures, results of a lift-lower cycle of the boom and bucket cylinders with a low and a high load with oil temperature of $40{ }^{\circ} \mathrm{C}$ are shown as the examples. These loads are $1 / 4$ and about $3 / 4$ of the maximum load limited by the pressure relief valves. The oil temperature of $40{ }^{\circ} \mathrm{C}$ for these examples was chosen as it is in the range of the most commonly expected running temperature of hydraulic oil, from about $40-60{ }^{\circ} \mathrm{C}$ and nominal oil viscosities are most commonly given at temperature of $40^{\circ} \mathrm{C}$.

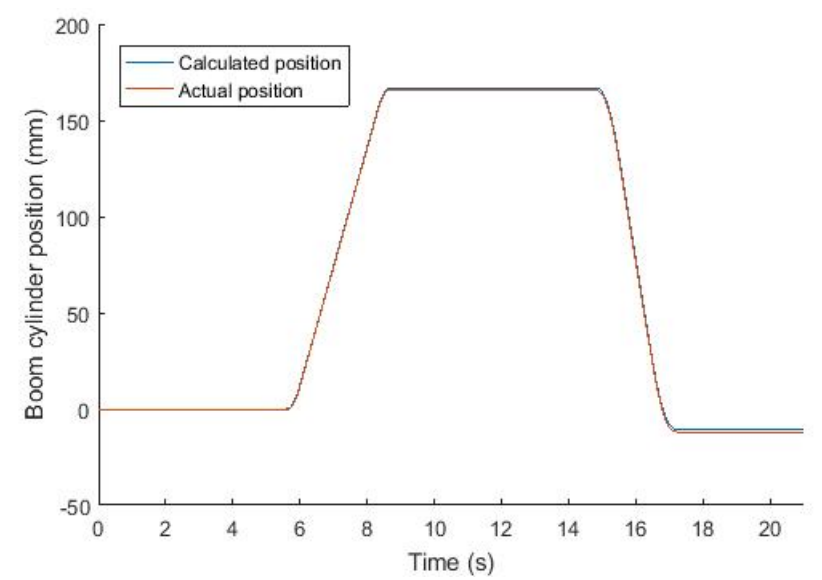

Figure 11. Calculated and actual simulation boom cylinder position with cylinder 1/4 load of $129 \mathrm{kN}$ and oil temperature of $40^{\circ} \mathrm{C}$.

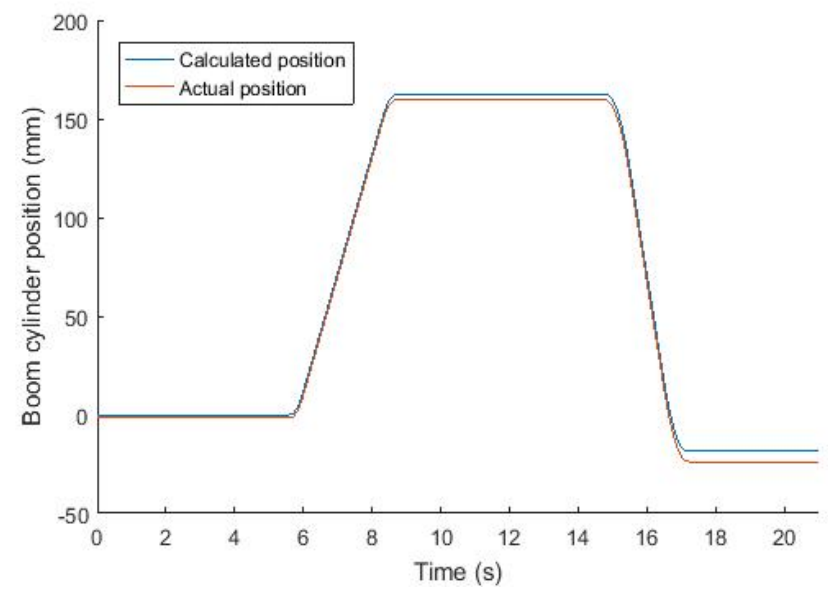

Figure 12. Calculated and actual simulation boom cylinder position with $3 / 4$ cylinder load of $441 \mathrm{kN}$ and oil temperature of $40^{\circ} \mathrm{C}$

Figures 13 and 14 show the graphs for the bucket cylinder with the same conditions. As mentioned, the lift direction of the cylinder is retraction.

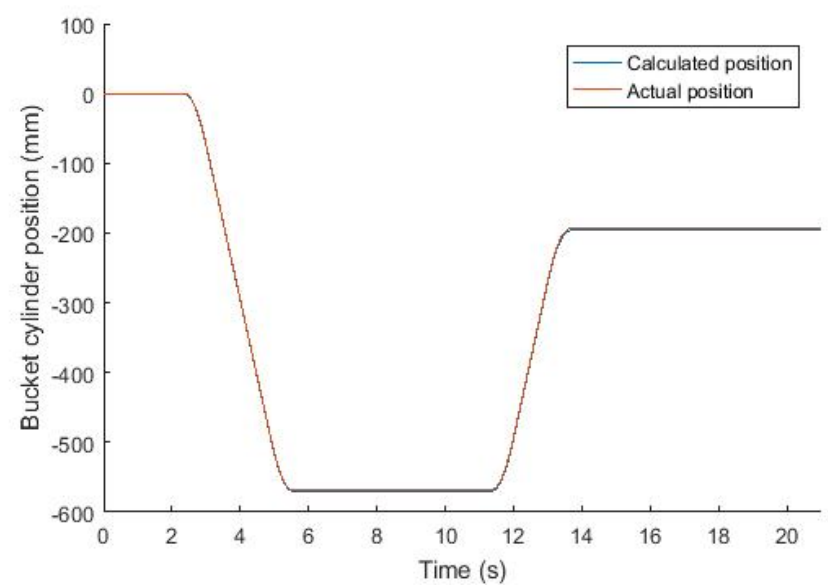

Figure 13. Calculated and actual simulation bucket cylinder position with cylinder 1/4 load of $48 \mathrm{kN}$ and oil temperature of $40^{\circ} \mathrm{C}$.

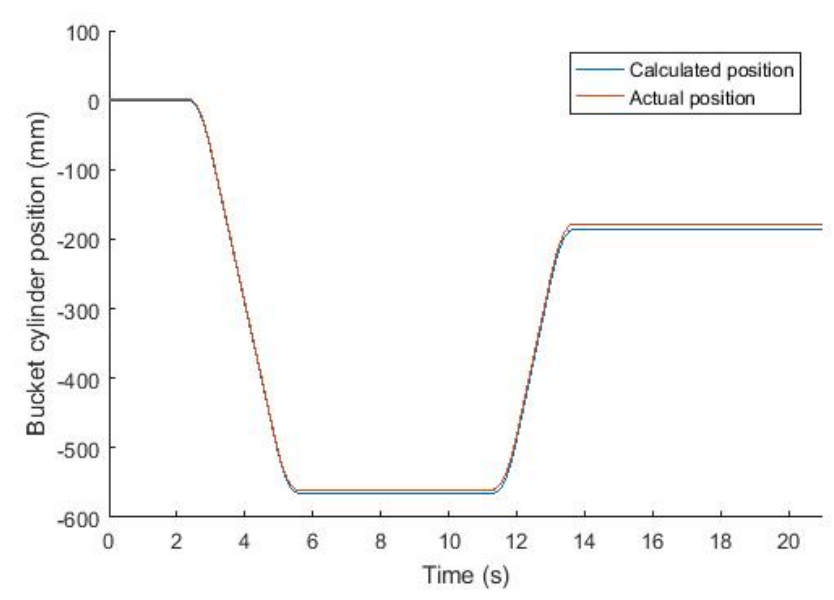

Figure 14. Calculated and actual simulation bucket cylinder position with cylinder $3 / 4$ load of $162 \mathrm{kN}$ and oil temperature of $40^{\circ} \mathrm{C}$. 
Figures 15 and 16 present the errors of the boom and bucket cylinder positions at various load levels. The light load is again $1 / 4$, medium is $1 / 2$ and high is about $3 / 4$ of the maximum theoretical cylinder load.

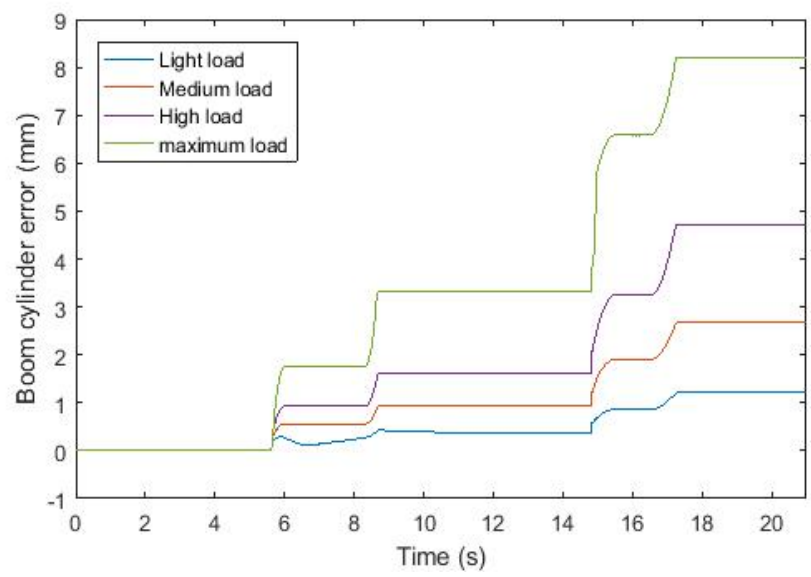

Figure 15. Error between the actual simulation and calculated boom cylinder position at various load levels at oil temperature of $40^{\circ} \mathrm{C}$.

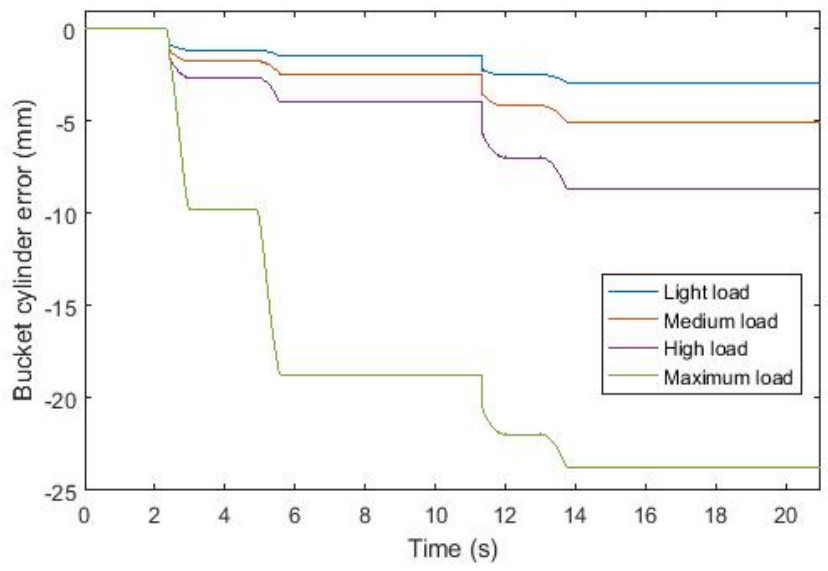

Figure 16. Error between the simulation true and calculated bucket cylinder position at various load levels at oil temperature of $40^{\circ} \mathrm{C}$.

\section{Discussion}

Presented sensorless position study based on DDH was illustrated for a mining loader case, however, it can also be extended for stationary application.

Based on the simulation results, the sensorless positioning of this DDH system provides sufficient accuracy within tested conditions for a single lifting lowering work cycle and chosen medium load. Best achieved accuracy was within a few millimeters for a single cylinder. During the movement, the position calculation accumulates no error as the calculation process is based on simulation of the cylinder movement with constant motor speed. However, there is a notable accumulation of error, which is mainly caused by errors induced during the motor acceleration and deceleration phases. A typical work cycle of a mining loader consist of lifting a load and dumping it during which the cylinder pistons will certainly reach the end- points or pass through the middle. Therefore, this error for repeated cycles can be resolved by adding simple proximity sensors in the cylinder end or middle points to be used as reference points for the sensorless position calculation.

It is also useful to discuss the degree of accuracy needed. In conventional systems, direct measurement of cylinder position provides the greatest accuracy at the cost of more expensive sensor equipment. However, if millimeter scale accuracy is not needed and centimeters are enough, sensorless positioning is likely viable and cheaper. However, direct driven servo hydraulics are needed to implement sensorless positioning of cylinders. Also depending on the layout of the DDH system, more pump units are needed if multi-pump system is chosen. In this study, the efficiency of the energy storage and power electronics were not considered in this stage of research. Consequently, DDH brings advantages such as sensorless position control but also disadvantages with requirements of more components and extra expenses. However, further investigation of these components will be included in close future.

As such, if direct driven hydraulics are utilized to drive a cylinder, sensorless positioning almost comes with it. If parameters of a single DDH unit and the actuator it drives are known, it is easier to simulate and predict the behavior of the system since at known pressure level and flow rate the cylinder moves at constant speed and a constant pump motor torque and rotational speed is required for this. However, in some cases it could be difficult to obtain all the necessary information to build accurate simulation models of a given system.

In this study, pump leakages were assumed to match the manufacturer datasheets. Pump leakages are mainly dependent on fluid viscosity and pressure, which makes behavior more predictable. Only inaccuracies that remain are how accurately the pump volumetric and mechanical efficiencies as well as frictions are defined by the manufacturer. This becomes a significant source of error in a more unknown system. The cylinder friction was also based on assumptions of previous friction measurements with a smaller cylinder, which is likely to provide in some amount inaccurate values. Measurements with the mining loader will be executed for more accurate friction values. In a real life system, factors such as seal wear cause additional non-linearity sources, which can be difficult to predict unless accurate wear models are taken into account. In addition, properties of the oil change with time as the oil ages and impurities from various sources mix in. Thus, it will be easier to implement a sensorless positioning logic into an EHA unit designed from scratch where all relevant parameters are known. If the cylinder is separate, additional measurements will be needed to define friction.

\section{Conclusion}

This study researched the viability and methods of sensorless position control of direct driven hydraulic 
cylinder via simulation model. Simulation results of comparing the actual and calculated cylinder position during a single lift-lower cycle showed an accumulated error at high load within about $5 \mathrm{~mm}$ for the boom cylinder and about $10 \mathrm{~mm}$ for the bucket cylinder. The error was smaller at lower loads. The notable error accumulation and problems near and over the maximum pressure limits would require means of providing a reference point, for example with proximity sensors. Further research is needed to validate the simulation results by performing test measurements with the real DDH units.

\section{Acknowledgements}

This research was enabled by the financial support of Tekes, the Finnish Funding Agency for Technology and Innovation, (project EL-Zon) and internal funding at the Department of Mechanical Engineering at Aalto University. The cooperation with Lehmuspelto Teemu and Tammisto Otto is highly appreciated. 


\section{Nomenclature}

\begin{tabular}{|c|c|c|}
\hline Designation & Denotation & Unit \\
\hline$F_{p}$ & Piston force & {$[\mathrm{N}]$} \\
\hline$p_{A}$ & A-side pressure & {$[\mathrm{Pa}]$} \\
\hline$p_{B}$ & $\mathrm{~B}$-side pressure & {$[\mathrm{Pa}]$} \\
\hline$A_{c y l \_A}$ & Piston A-side area & {$\left[\mathrm{m}^{2}\right]$} \\
\hline$A_{c y l \_B}$ & Piston B-side area & {$\left[\mathrm{m}^{2}\right]$} \\
\hline$\eta_{h m_{-} \_y l}$ & $\begin{array}{l}\text { Cylinder hydro-mechanical } \\
\text { efficiency }\end{array}$ & \\
\hline$\eta_{v_{-} c y l}$ & Cylinder volumetric efficiency & \\
\hline$v_{c y l}$ & Cylinder piston velocity & {$[\mathrm{m} / \mathrm{s}]$} \\
\hline$Q_{p}$ & Pump flow & {$\left[\mathrm{m}^{3} / \mathrm{s}\right]$} \\
\hline$\eta_{v-p}$ & Pump volumetric efficiency & \\
\hline$\eta_{h m p}$ & $\begin{array}{l}\text { Pump hydro-mechanical } \\
\text { efficiency }\end{array}$ & \\
\hline$V_{p}$ & Pump displacement & {$\left[\mathrm{m}^{3} / \mathrm{rev}\right]$} \\
\hline$T_{p}$ & Pump torque & {$[\mathrm{Nm}]$} \\
\hline$\tau_{\text {Fric }}$ & Friction torque & {$[\mathrm{Nm}]$} \\
\hline$\tau_{0}$ & No-load torque & {$[\mathrm{Nm}]$} \\
\hline$K_{T P}$ & $\begin{array}{l}\text { Friction torque vs pressure } \\
\text { gain coefficient }\end{array}$ & {$[\mathrm{Nm} / \mathrm{pa}]$} \\
\hline$\Delta p$ & Pump pressure gain & {$[\mathrm{Pa}]$} \\
\hline$\Delta p_{\text {Nom }}$ & Nominal pump pressure gain & {$[\mathrm{Pa}]$} \\
\hline$\omega$ & Pump angular velocity & {$[\mathrm{rad} / \mathrm{s}]$} \\
\hline$\omega_{\text {Nom }}$ & $\begin{array}{l}\text { Nominal pump angular } \\
\text { velocity }\end{array}$ & {$[\mathrm{rad} / \mathrm{s}]$} \\
\hline$\omega_{\text {Thresh }}$ & $\begin{array}{l}\text { Threshold angular velocity } \\
\text { between pump and motor } \\
\text { mode transition }\end{array}$ & {$[\mathrm{rad} / \mathrm{s}]$} \\
\hline$\eta_{v, N o m}$ & Nominal volumetric efficiency & \\
\hline$\eta_{T o t}$ & Total efficiency & \\
\hline$q_{\text {Leak }}$ & Leakage flow & {$\left[\mathrm{m}^{3}\right]$} \\
\hline$K_{H P}$ & Hagen-Poiseuille coefficient & \\
\hline$v_{\mathrm{Nom}}$ & $\begin{array}{l}\text { Nominal oil kinematic } \\
\text { viscosity }\end{array}$ & {$\left[\mathrm{m}^{2} / \mathrm{s}\right]$} \\
\hline$\rho_{\mathrm{Nom}}$ & Nominal oil density & {$\left[\mathrm{kg} / \mathrm{m}^{3}\right]$} \\
\hline$\rho$ & Current oil density & {$\left[\mathrm{kg} / \mathrm{m}^{3}\right]$} \\
\hline
\end{tabular}

\section{References}

[1] E. E. Herceg. Taking a Position on Hydraulic Cylinder Sensors. Alliance Sensors Group. Hydraulics \& Pneumatics. 2015. Available: http://hydraulicspneumatics.com/cylindersactuators/taking-position-hydraulic-cylinder-sensors

[2] A. Consoli, G. Bottiglieri, R. Letor, R. Ruggeri, A. Testa, S. De Caro. Sensorless Position Control of DC Actuators for Automotive Applications. IAS 2004. MIUR-PRIN 2003: Innovative conversion topologies for electric drives.

[3] Pedro, A, Goodwin G. Virtual Sensors for Control Applications. Annual Reviews in Control 26 (2002) 101-112.

[4] Manring, N. Hydraulic Control Systems. Hoboken, N.J: John Wiley \& Sons, 2005. 446 p. ISBN 0-47169311-1

[5] S. Habibi. A. Goldenberg. Design of a New HighPerformance ElectroHydraulic Actuator. IEEE/ASME TRANSACTIONS ON MECHATRONICS, VOL. 5, NO. 2, JUNE 2000. P. 158-164

[6] K. Heybroek. Saving Energy in Construction Machinery using Displacement Control Hydraulics, Concept Realization and Validation. PHD Thesis. Linköping University, Division of Fluid and Mechanical Engineering Systems, Department of Management and Engineering. Lingköping. 2008. 127 p.

[7] T. Minav, C. Bonato, P. Sainio \& M. Pietola. Direct Driven Hydraulic Drive. In: The 9th International Fluid Power Conference. 2014

[8] C. Bonato, T. Minav, P. Sainio, M. Pietola. Position control of direct driven hydraulic drive. Proceedings of the 8th FPNI Ph.D Symposium on Fluid Power, FPNI2014. 2014, June 11-13, 2014, Lappeenranta, Finland

[9] T. Minav, L. Laurila, J. Pyrhönen. Relative position control in an electro-hydraulic forklift. International Review of Automatic Control (I.RE.A.CO.), Vol. X, $n$. X. 2012

[10]A. Järf. Flow compensation using hydraulic accumulator in direct driven hydraulic differential cylinder application and effects on energy efficiency. Master's thesis. Aalto University, School of Engineering. Espoo 2016. 102 p. 
[11] Hydac. Medium heavy duty series size 2 PGI100. http://www.hydac.com/fileadmin/pdb/pdf/PRO000000 0000000000000002905010012.pdf. Visited on: 5.2 .2017

[12] Parker. SCPT-CAN Pressure/Temperature sensor. https://promo.parker.com/parkerimages/promosite/Sen soControl/UNITED \%20STATES/About $\%$ 20SensoControl/PDF/SCPT-CAN-Manual.pdf. Visited on: 5.2.2017

[13]JUMO. CANtrans TRTD temperature probe with CANopen output. https://www.jumo.net/attachments/JUMO/attachmentd ownload?id=4533. Visited on: 5.2.2017

[14] Posital Fraba. LINARIX Linear Sensor. https://www.posital.com/en/products/linearsensors/linarix-product-finder/LM0-CA00B-12122C00-PAM/125004001/detail.php. Visited on: 5.2 .2017

[15] Altairnano. 24V 60Ah Battery module. http://www.altairnano.com/products/battery-module/. Visited on: 5.2.2017

[16] T. Minav, T. Lehmuspelto, P. Sainio, M. Pietola. Series hybrid Mining loader with zonal hydraulics. $10^{\text {th }}$ International Fluid Power Conference. 2016

[17] T. Schimmel. Efficiency of Hydraulic Fluids - Theory and Field Testing. Evonik Oil Additives. Evonik Industries. Helsinki 2013.

[18] Shell Lubricants. Shell Tellus oils T Technical datasheet.

http://www.epc.shell.com/Docs/GPCDOC X cbe 248 55 key 140002044283 6623.pdf. Visited on: 12.11 .2016

[19] The MathWorks Inc. Fixed-Displacement Pump. 2016. https://se.mathworks.com/help/physmod/hydro/ref/fix eddisplacementpump.html. Visited on: 5.2.2017 